\title{
A EXPERIÊNCIA DE CONSUMO DE APLICATIVOS DE TRANSPORTE PARTICULAR: UM ESTUDO NA CIDADE DE RECIFE
}

\author{
THE CONSUMPTION EXPERIENCE OF APPLICATIONS OF PRIVATE \\ TRANSPORTATION: A STUDY IN THE CITY OF RECIFE
}

Natália Karine Almeida de Jesus ${ }^{1}$

Angela Cristina Rocha de Souza ${ }^{2}$

Ionete Cavalcanti de Moraes ${ }^{3}$

Maria Iraê de Souza Corrêa 4

1

Graduanda em

Administração pela

Universidade Federal

Rural de Pernambuco.

Foi bolsista PIBIC/CNPq/

UFRPE por dois anos

consecutivos (2017-2019)

atuando nas seguintes áreas:

Estratégias empresariais

e Mercadologia.

2

Professora associada I da Universidade Federal Rural

de Pernambuco (UFRPE)

no Departamento de

Administração (DADM)

Doutora e Mestre em

Administração pela

Universidade Federal de

Pernambuco (UFPE), e

graduada em Engenharia

Química pela mesma

instituição. Especialista

em Administração

Financeira pela Faculdade

de Administração de

Pernambuco/UPE.

3

Possui graduação em

Administração de Empresas

pela Universidade Federal

da Paraíba (1991), mestrado

em Administração

pela Universidade

Federal de Pernambuco

(2004), e Doutorado em

Administração pela

Universidade Federal de

Pernambuco (2013).

4

Possui graduação em

Ciências Sociais pela

Universidade de São

Paulo (1983), mestrado

em Administração

pela Universidade

Federal de Pernambuco

(2007) e doutorado em

Administração pela

Universidade Federal de

Pernambuco (2013).
RESUMo: Este estudo teve como objetivo analisar a experiência de consumo de usuários de aplicativos voltados à mobilidade urbana, especificamente os de transporte particular. Desenvolvemos uma pesquisa descritiva e qualitativa cujos dados foram analisados utilizando-se da análise de conteúdo. Os resultados ratificam os elementos indicados por Lofman (1991), com exceção do elemento "estímulos sensoriais". Os significados e elementos da experiência encontrados sinalizam que o uso dos aplicativos vem preencher mais do que uma necessidade funcional de transporte. Eles atendem outras necessidades, afetivas, relacionadas ao bem estar do consumidor que envolvem, por exemplo, ficar tranquilo e sentir segurança. Concluímos que o uso do aplicativo extrapola a perspectiva racional do consumo, incorporando também os aspectos de natureza sociocultural, significados e sentimentos. Assim, esse estudo contribui para diminuir a lacuna de conhecimento que envolve a compreensão dos elementos que compõem a experiência de consumo de produtos tecnológicos, ao identificar a presença de aspectos emocionais no consumo desses produtos.

Palavras-chave: Experiência de consumo; Comportamento do consumidor; Consumo de tecnologia; Aplicativos de transporte particular.

ABSTRACT: This study aimed to analyze the users consumption experience of applications for urban mobility, specifically those of private transport. It was developed a descriptive and qualitative research whose data were analyzed using content analysis. The results ratify the elements indicated by Lofman (1991), except for the "sensory stimuli" element. The meanings and elements of experience found indicate that the use of applications meets more than a functional need for transportation. They address other needs, affectives, consumer welfare related that involve, for example, being calm and feeling safe. As a conclusion, the use of the application goes beyond the rational perspective of consumption, incorporating also the socio-cultural aspects, meanings and feelings. Thus, this study contributes to reduce the knowledge gap that involves the understanding of the elements that make up the consumption experience of technological products by identifying the presence of emotional aspects in their consumption.

KEYWORDS: Consumption experience; Consumer behavior; Technology consumption; Applications of private transportation. 


\section{INTRODUÇÃO}

As tecnologias da informação e comunicação têm se incorporado, de modo crescente, às atividades cotidianas dos cidadãos brasileiros. De acordo com uma pesquisa realizada pela Fundação Getúlio Vargas, em maio de 2018, havia no Brasil 220 milhões de smartphones, ou seja, mais de um dispositivo por habitante (FGV, 2018). Estes, por sua vez, possuem diversas funcionalidades, provenientes de aplicativos que atuam como facilitadores na vida dos usuários possibilitando realizar tarefas como transações bancárias, compras, ou ainda disponibilizando informações sobre o trânsito em tempo real.

Uma dessas funcionalidades disponibilizadas diz respeito ao uso de aplicativos voltados à mobilidade urbana. Segundo a pesquisa "Observatório Global de Mobilidade", da Kantar TNS publicada em $2017,75 \%$ das pessoas em áreas urbanas utilizam aplicativos para organizar ou orientar seu trajeto (KANTAR TNS, 2017). Tendo em vista as dificuldades presentes no trânsito brasileiro, esses aplicativos atuam como uma ferramenta para melhoria da mobilidade das pessoas, oferecendo informações e formas de deslocamento.

Diante dessa perspectiva, surge a necessidade de compreender como os consumidores, usuários, se relacionam com esses aplicativos. Estudos que buscam entender a relação entre consumidores e produtos/serviços geralmente enfatizam o processo de escolha e tomada de decisão de compra. Porém, de acordo com Zilles (2006), de modo geral, esses estudos têm como pressuposto um consumidor racional, desconsiderando os aspectos emocionais que também fazem parte das decisões sobre o consumo. Como base para tais estudos está o princípio de racionalidade moderna que negligencia aspectos relevantes como a busca por sensações e benefícios emocionais.

Nesse sentido, Holbrook e Hirschman (1982) introduziram a perspectiva da experiência para a compreensão dos fenômenos do consumo. Esta perspectiva é caracterizada por aspectos emocionais, conduzida por um fluxo de fantasias, sentimentos e diversão durante o consumo. Ao estudar a experiência de consumo, alguns autores tratam dos elementos que a envolvem, abordando não apenas os aspectos racionais. De acordo com Schmitt (2004), uma experiência possui elementos que englobam desde o que os consumidores sentem, fazem, observam, até o que pensam no momento em que consomem. Conhecer esses elementos possibilita uma compreensão maior do processamento afetivo do consumidor durante o consumo.

Em seu trabalho sobre o consumo de produtos tecnológicos, Souza (2010) discute a necessidade de se compreender melhor a relação dos consumidores com as tecnologias face às características da sociedade contemporânea. Para McCarthy e Wright (2004), o estudo do consumo de tecnologia possibilita tratar diversas perspectivas acerca das práticas socioculturais que envolvem a utilização de produtos tecnológicos. Nesse sentido, Giesler e Venkatesh (2005) enfatizam que estudos 
que adotam o princípio supracitado da racionalidade moderna, não respondem à necessidade de compreensão do consumo de tecnologias, por não considerarem a natureza sociocultural do consumo e deixarem de fora aspectos como os significados e experiências advindos desse consumo. Assim, embora o tema da experiência venha sendo estudado desde o trabalho inicial de Holbrook e Hirschman (1982), observamos uma lacuna de estudos nessa perspectiva aplicados ao consumo de serviços permeados pela tecnologia, mais especificamente por aplicativos.

Investigações como a de Dusi (2016), por exemplo, confirmam essa lacuna ao investigarem as razões que levam os consumidores dos aplicativos 99Taxis e Uber a escolher e utilizar um ou outro e qual o nível de satisfação do usuário com relação ao serviço oferecido pelo aplicativo, sem levar em consideração significados e experiências advindos desse consumo. Já Li, Dong e Chen (2012) ressaltaram que poucos estudos sobre o comércio móvel (m-commerce) focam nos aspectos experienciais do consumo entre usuários de dispositivos móveis. Estes exemplos demonstram a necessidade de investigações que compreendam como ocorre a experiência de consumo de usuários de aplicativos.

Considerando as lacunas observadas, o presente trabalho possui o seguinte objetivo: analisar a experiência de consumo de usuários de aplicativos voltados à mobilidade urbana. Este estudo mostra-se relevante, do ponto de vista teórico, pois pode contribuir para ampliar o conhecimento acerca da experiência do consumidor, trazendo informações que contribuam para compreender o papel da experiência no comportamento do consumidor. Do ponto de vista prático, a compreensão da experiência do consumidor com os aplicativos voltados à mobilidade urbana pode ajudar as empresas a desenvolverem estratégias que atendam melhor a necessidade dos consumidores e a gerenciar a experiência do cliente.

Tendo em vista o, estudo desenvolvido pela empresa especializada em navegação TomTom, em 2017, que apontou o trânsito do Recife como o décimo primeiro pior do mundo e o primeiro pior do país (TOMTOM, 2017), optamos por concentrar a pesquisa nos aplicativos que abrangem a cidade de Recife.

\section{REFERENCIAL TEÓRICO}

A visão experiencial de consumo, antes negligenciada, foi pioneiramente tratada pelos autores Holbrook e Hirschman (1982) que definiram a experiência de consumo como um fenômeno voltado para a busca de fantasias (sonhos, imaginação, desejos inconscientes), sentimentos (emoções tais como amor, ódio, raiva, inveja, divertimento) e diversão (prazer hedônico derivado de atividades divertidas, alegres e prazerosas). Essa visão associada aos processos cognitivos durante o consumo, ampliava a noção de consumo apenas racional até então percebida. Reforçando, Addis e Holbrook (2001) ressalvam que pode se reconhecer, no comportamento do consumidor, a atuação de processos afetivos quando aspectos antes negligenciados são incorporados 
à racionalidade. Desse modo, temos um consumidor que é conduzido tanto por emoções quanto por ações racionais.

De acordo com Barbosa (2006), muitos significados são atribuídos à palavra experiência. Os que melhor se ajustam a esta pesquisa provêm das áreas da Sociologia e Psicologia, que "entendem a experiência enquanto uma atividade cognitiva e subjetiva que permite a construção da realidade e sua verificação" (CORREA; PINTO; BATINGA, 2016, p. 375). Na perspectiva de Schmitt (1999), uma experiência apresenta a individualidade como principal fator por produzir sempre uma resposta diferente ao estímulo, ou seja, em cada consumidor podem ser alcançados significados diferentes. Complementando, Pine e Gilmore II (1998) afirmam que a experiência é inerentemente individual ao consumidor que se envolve de forma física, intelectual, espiritual ou ainda emocional em uma atividade de consumo. Já Correa, Pinto e Batinga (2016, p. 20), ao pesquisar experiências vivenciadas por deficientes visuais ao usarem produtos/serviços de estética, identificaram que "cada grupo social é singular na (re)construção e manipulação dos significados, ou seja, o mesmo produto ou serviço pode ter significados construídos social e culturalmente de forma diversa."

No intuito de compreender as experiências de consumo, diferentes abordagens foram aplicadas ao assunto. Alguns autores como Pine e Gilmore II (1998) e Schmitt (2000) procuraram definir os tipos de experiências vivenciadas pelos consumidores, enquanto outros (e.g., HOLBROOK, 2000; LOFMAN, 1991; SCHMITT, 2004) avaliam os elementos ou componentes de uma experiência de consumo. Esse último aspecto está diretamente relacionado ao objetivo dessa pesquisa e será abordado no tópico a seguir.

\section{ELEMENTOS DE UMA EXPERIÊNCIA DE CONSUMO}

Ao estudar uma experiência de consumo, autores (e.g., KRANZBÜHLER et al., 2018; LOFMAN, 1991; SCHMITT, 2004) veem a experiência como uma estrutura multidimensional composta por diferentes elementos. Gentile, Spiller e Noci (2007) salientam, porém, que tal estrutura não é reconhecida pelo cliente e o que se espera é que os clientes percebam a experiência com um sentido único, sem fazer distinção entre os elementos. Compreender, porém, cada elemento, possibilita às organizações formas de gerenciar a experiência do consumidor (PALMER, 2010) de forma que possam criar mais valor para os consumidores e obter uma vantagem competitiva perante os concorrentes.

Holbrook (2000) reforçou o entendimento proposto em sua obra anterior com Hirschman (1982) em que reconhecem como elementos que compõem uma experiência as fantasias, sentimentos e diversões. Schmitt (1999), por sua vez, propôs cinco módulos experienciais estratégicos (MEE's) que envolvem as experiências, são eles: sensorial (sentido); afetivo (sentimento); criativo-cognitivo (pensamento); físico 
(ação); e experiências de identidade social que resultam da relação com um grupo de referência ou cultura. Para Schmitt (2004), tais elementos compreendem o que os consumidores registram e experimentam enquanto consomem considerando a forma como se sentem, pensam, o que fazem e veem. Para Kranzbühler et al. (2018), a experiência do cliente é um construto abrangente que envolve componentes sociais, físicos ou sensoriais, respostas afetivas e avaliações. Podemos observar que cada autor acima citado apresenta uma tipologia diferente das experiências, ainda que estas se assemelhem de alguma forma. Todos esses aspectos, porém, estão presentes na obra de Lofman (1991), que propõe uma classificação composta por seis elementos interdependentes: contexto, estímulos sensoriais, respostas afetivas, processos cognitivos, atividades e avaliação os quais descrevemos a seguir.

Para Lofman (1991), o contexto é um elemento que permite descrever o ambiente em que a experiência ocorre, de modo que as pessoas, objetos e até aspectos intangíveis (como: "primavera", "sala escura"), criam a experiência. Bitner (1992), por outro lado, tratam do contexto como ambiente físico, onde as condições ambientais, espaço e símbolos como: temperatura, barulho, odor, equipamentos, decorações são fatores que percebidos no ambiente provocam respostas diferentes a cada evento. Quanto aos estímulos sensoriais, eles correspondem a uma tradução de ofertas do mercado por meio de sensações, como: ouvir, ver, provar, cheirar e tocar (LOFMAN, 1991). De acordo com Álvares (2004), a tomada de decisão sofre direta influência desses estímulos sensoriais e a opção com maior volume de estimulações tende a ser a preferida. Já Madzharov, Block e Morrin (2015) discorrem sobre o uso de gatilhos subconscientes que apelam aos sentidos humanos para criar uma experiência de consumo sensorial. Os resultados da pesquisa demonstram que o estímulo sensorial olfativo, o uso de perfume, influencia na percepção espacial da densidade social e trazem evidências de como os aromas afetam o comportamento de compra.

Os processos cognitivos referem-se à percepção de atributos, benefícios e associações no consumo, ou seja, são os pensamentos do consumidor estimulados pelo consumo do produto ofertado (LOFMAN, 1991). Os atributos envolvem aspectos tanto físico (tamanho) como abstratos (qualidade, durabilidade) que são percebidos na oferta de mercado. Já os benefícios ou desvantagens referem-se ao modo como a oferta de mercado satisfaz as necessidades e desejos pessoais do consumidor. Lofman (1991) complementa, classificando os benefícios em funcionais, quando seguem a uma finalidade específica a ser satisfeita através do consumo do produto (por exemplo, emagrecimento e prevenção de rugas), e em psicológicos, quando estes benefícios se relacionam às necessidades sociais como autoestima, status e realização. Por último, os processos cognitivos para Lofman (1991) envolvem associações que ligam uma oferta de mercado a outras ofertas, objetos, símbolos, conceitos, pessoas, lugares ou eventos, que não são de fato ligados à experiência de consumo. 
O elemento respostas afetivas, de acordo com Lofman (1991), é formado pelos diversos sentimentos (medo, inveja, orgulho) despertados pelo consumo e pelas alterações de estado de humor (curioso, apaixonado, malicioso) durante a experiência do consumidor, e ainda por sentimentos fisiológicos, organicamente derivados (com fome, cansado, enjoado) e organicamente relacionados (estimulado, relaxado). Esse elemento contempla melhor os sentimentos e emoções que estão presentes no consumo, com relação ao marketing tradicional que, segundo Holbrook e Hirschman (1982) considerava o aspecto afetivo apenas como o fato de gostar ou não de uma marca e de sua posição no ranking com as demais marcas. Um estudo de Li, Dong e Chen (2012) sobre fatores que influenciam a experiência de consumo no comércio em dispositivos móveis indicou que a emoção desempenha um papel significante nessa experiência de consumo. As dimensões da emoção prazer e excitação tiveram um impacto positivo na atividade, intenção ou outra reação dos consumidores relacionada à compra.

Quanto ao elemento atividades, Lofman (1991) o descreve como eventos relacionados ao comportamento do consumidor que ocorrem durante o consumo. Ele classifica essas atividades em mentais, quando consiste no processamento de informações como: "Pensar sobre a outra pessoa com quem estou falando" e "Escolher os melhores itens disponíveis" e em atividades motoras, quando durante o consumo ocorre movimentos físicos como: "Nadar no oceano", "vestir-se". O último elemento proposto por Lofman (1991), avaliação, diz respeito à avaliação geral feita pelo consumidor ao usufruir de uma oferta de mercado. $\mathrm{O}$ consumidor gera respostas avaliativas que podem ter ligações com o uso, resultados alcançados, compra ou posse da oferta, gerando avaliações como, por exemplo, "satisfeito"; ou ainda estar relacionadas com a apreciação da oferta, gerando respostas como: "diversão", "entretenimento" ou "algo incrível". Nesse sentido, estudo desenvolvido por Damian e Merlo (2014) objetivou analisar o papel da qualidade do serviço e da imagem da loja na experiência de consumo de serviços automotivos. Os resultados evidenciaram a relevância da imagem da loja e da qualidade dos serviços na avaliação de uma experiência de consumo agradável.

\section{PROCEDIMENTOS METODOLÓGICOS}

Este estudo foi desenvolvido por meio de uma pesquisa descritiva, de cunho qualitativo. Para a realização do objetivo geral da pesquisa, inicialmente identificamos aplicativos voltados à mobilidade urbana disponíveis no mercado. Para isso, realizamos um levantamento por meio das lojas de aplicativos online Play Store e Apple Store utilizando os seguintes termos de busca: "Mobilidade urbana”, "Transporte público", "Transporte particular", "Rotas de ônibus", "Trânsito Recife", "Aplicativos de táxi Recife".

Para identificar os elementos da experiência de consumo de usuários de aplicativos voltados à mobilidade urbana e os significados 
associados à experiência, foi realizada uma coleta de dados por meio de entrevistas semiestruturadas com usuários de aplicativos selecionados no primeiro objetivo específico. Na elaboração das questões do roteiro a ser aplicado nas entrevistas semiestruturadas, tomamos como base os elementos da experiência de consumo apresentados em Lofman (1991). O estudo de Lofman (1991) foi escolhido por contemplar os elementos da experiência de consumo presentes em outros estudos. $\mathrm{O}$ roteiro foi composto por perguntas abertas relacionadas aos elementos da experiência de consumo e seu significado, e por perguntas fechadas sobre o perfil dos entrevistados. Foi realizada uma entrevista pré-teste para avaliar a compreensão do roteiro desenvolvido e adequação das questões. Na seleção dos entrevistados, utilizamos uma amostra de conveniência (GUIMARÃES, 2008) onde os participantes da pesquisa foram selecionados por acessibilidade.

O corpus foi composto pelas informações coletadas no levantamento referente aos aplicativos voltados à mobilidade urbana disponíveis no mercado e ainda pela transcrição das entrevistas realizadas com os usuários dos aplicativos selecionados para a pesquisa. Os dados coletados no levantamento realizado nas lojas online foram classificados conforme sua funcionalidade e agrupados em um quadro. A análise dos dados coletados nas entrevistas, foi feita de forma qualitativa utilizando-se a técnica da análise de conteúdo. O software Atlas.Ti 7 foi utilizado como suporte à análise.

\section{ANÁLISE DOS RESULTADOS}

\section{APLICATIVOS VOLTADOS À MOBILIDADE URBANA DISPONÍVEIS NA CIDADE DE RECIFE}

Para a identificação dos aplicativos voltados à mobilidade urbana disponíveis no mercado, realizamos um levantamento, em fevereiro de 2018, nas lojas Play Store e App Store. Durante a coleta, observamos que os aplicativos diferem quanto a sua abrangência de atuação. Por exemplo, o aplicativo "Moovit" possui abrangência internacional enquanto outros possuem abrangência local ou ainda atendem algumas cidades ou uma região específica, como "CittaMobi", "Mary Drive Passageira". Assim, focalizamos a pesquisa nos aplicativos que abrangem a cidade de Recife, tendo em vista que, estudo desenvolvido pela empresa especializada em navegação TomTom, em 2017, apontou o trânsito do Recife como o décimo primeiro pior do mundo e o primeiro pior do país (TOMTOM, 2017).

Foram observados nas lojas virtuais 22 aplicativos disponíveis para download. Estes, por sua vez, apresentam diferentes funcionalidades como: serviço de transporte particular, orientação de trajetos, serviços de táxi, aluguel de bicicletas, serviço de carona e informações relativas ao transporte público coletivo, conforme apresentado no Quadro I. 


\section{Revista de Gestão Pública}

Quadro 1. Aplicativos disponíveis para download na Play Store e Apple Store que abrangem a cidade de Recife

\begin{tabular}{|c|c|c|}
\hline Qtde. & Aplicativos & Funcionalidade \\
\hline 5 & 99, Mary Drive Passageira, T81, Uber, Yet Go & Serviço de transporte particular \\
\hline 5 & $\begin{array}{l}\text { Bus Legal Recife, CittaMobi, MeuBusão Recife, Moovit, } \\
\text { Recife Bus }\end{array}$ & $\begin{array}{l}\text { Informações relativas ao transporte público } \\
\text { coletivo }\end{array}$ \\
\hline 2 & Maps: Gps e Transporte público, Waze & Orientação de trajetos \\
\hline 5 & $\begin{array}{l}\text { Disk Taxi Recife, Easy, Recife Radio Taxi, Servi Taxi } \\
\text { Recife, Teletaxi Recife }\end{array}$ & Serviço de táxi \\
\hline 4 & Blablacar, Beep me, Bynd, Zumpy & Serviço de carona \\
\hline 1 & Bike Itaú & Aluguel de bicicleta \\
\hline
\end{tabular}

FONTE: Elaborado pelas autoras com base nas informações disponíveis nas lojas online de apps (2018).

Considerando o elevado número de downloads alcançado pela empresa Uber e ainda o número de usuários do aplicativo, que em 2017 alcançou treze milhões de usuários no Brasil (CAPELAS, 2017), decidimos focar a pesquisa nos aplicativos de transporte particular para realizar os demais objetivos da pesquisa, tendo em vista o uso disseminado desse tipo de aplicativo. Com relação a esses aplicativos, de uma maneira geral eles disponibilizam as mesmas funcionalidades: estimativa do preço, no de carros disponíveis, cor, placa e modelo do carro, tempo e distância da viagem. Todos os aplicativos encontrados possuem o download gratuito, já o serviço é cobrado, geralmente em um cartão de crédito cadastrado ou em dinheiro.

\section{OS ELEMENTOS E SIGNIFICADOS ASSOCIADOS À EXPERIÊNCIA DE CONSUMO} DE USUÁRIOS DE APLICATIVOS DE TRANSPORTE PARTICULAR

Para identificar os elementos da experiência de consumo de usuários de aplicativos de transporte particular, realizamos no período de abril a junho de 2018, dez entrevistas com usuários de aplicativos de serviços de transporte particular, onde os critérios para a entrevista foram: 1) Usar ou já ter utilizado algum dos aplicativos identificados e ser a pessoa responsável pelo manuseio no smartphone; 2) Residir na Região Metropolitana de Recife. Esclarecemos que só foram realizadas dez entrevistas porque observamos que os dados coletados começaram a se repetir.

Das dez pessoas entrevistadas todas afirmaram utilizar o aplicativo Uber e apenas quatro afirmaram que utilizam também o app 99, porém com menor frequência. Dentre os respondentes que dizem utilizar o 99 foi perguntado qual o 
critério de escolha entre os dois aplicativos e todos responderam que avaliam quem oferece o menor preço para o serviço desejado. Alguns respondentes, no entanto, afirmaram que apesar de às vezes encontrarem um valor mais baixo no 99, em função da pouca disponibilidade de carros têm que recorrer ao Uber, já que a espera pelo serviço da empresa 99 torna-se mais longa .

Com relação ao perfil dos entrevistados, todos eram solteiros e estudantes de universidades federais de Pernambuco. Apenas um entrevistado tem idade entre 26 e 35 anos e todo o restante tem idades entre 18 e 25 anos. Desses, quatro são do sexo masculino e seis do sexo feminino. Em relação à renda individual, os entrevistados não possuem renda, já que são estudantes, ou pertencem a diferentes faixas de renda que vão de $\mathrm{R} \$ 954,00$ a $\mathrm{R} \$ 5.764,00$.

Com as entrevistas realizadas, fizemos a análise dos elementos da experiência nos baseando na classificação de Lofman (1991). Estes elementos foram definidos como categorias de análise nas quais foram identificados outros elementos entendidos como subcategorias. Primeiramente, buscamos analisar os elementos presentes no "Contexto" de utilização do aplicativo. O contexto foi observado em dois sentidos: o primeiro foi relacionado à situação que leva as pessoas a solicitar o serviço, e o segundo foi relacionado ao contexto da utilização do aplicativo. No que se refere ao primeiro, ao perguntarmos: "Em quais situações você costuma solicitar o serviço?", surgiram como situações de uso mais frequentes: para ir a festas ou sair à noite, como informou o E2: "Ah, eu utilizo nos finais de semana, quando quero ir a festas ou à casa de amigos". E outras situações como o E8 relata: "Utilizo para ir a lugares que não conheço... quando eu não sei ir de ônibus prefiro ir de Uber... e até pelo horário por ser mais seguro que pegar ônibus". Outras situações foram identificadas na resposta do E9 que diz: "Geralmente pra ir a faculdade em dias de chuva, principalmente", e ainda na da entrevistada E7 que afirmou usar em ocasiões de atraso: "Já aconteceu de estar atrasada para uma consulta e pelo horário se torna mais fácil e viável solicitar um Uber" (E7).

Com relação ao "Contexto de utilização do aplicativo", surgiram alguns elementos como: o horário e a localização da chamada, conexão à internet e segurança que foram apontados pelos entrevistados como influenciadores na experiência de uso do aplicativo que pode se dar de diferentes maneiras a depender da ocorrência desses elementos (BITNER, 1992; LOFMAN, 1991). Os entrevistados geralmente solicitam o serviço da sua própria casa, porém em algumas ocasiões fazem a solicitação a partir de um outro ambiente como a rua, por exemplo. As falas dos respondentes nos ajudam a compreender a influência desses elementos. $\mathrm{O}$ entrevistado $\mathrm{E}_{3}$ salienta a dificuldade de conexão à internet na rua: "Há dificuldade no acesso à internet... em casa você tem o conforto do Wi-fi" (E3). O E5 reforça a questão da internet e aponta também o mau funcionamento do GPS do aplicativo, pois dependendo da localização da chamada, há dificuldade para a correta localização do 
cliente: "Sempre procuro um lugar com Wi-fi, então o local não interfere... mas às vezes da minha casa mesmo [com Wi-fi] há dificuldade na localização e o GPS parece não ficar bem localizado" (E5). A entrevistada Eıo enfatiza: "Às vezes pelo horário, você não consegue motorista, tem essa dificuldade". O entrevistado E2 traz a questão da insegurança do uso do aplicativo em ambientes públicos, indicando que a falta de segurança pública também influencia na experiência de consumo do aplicativo, como podemos ver na citação: : “(..) É mais fácil utilizar de casa, de casa é mais seguro para você utilizar o celular".

Observamos que os elementos conexão à internet e segurança fogem do controle das organizações que disponibilizam os aplicativos. Sendo primordial para o uso do aplicativo, a conexão à internet no país ainda é cara e de maneira geral de baixa velocidade. Tal aspecto, pode restringir o uso de forma mais ampla dos aplicativos pelo público alvo. O elemento segurança, salienta a questão da segurança pública nas cidades brasileiras.

Quanto aos "Estímulos sensoriais", que Lofman (1991) determina como uma tradução de ofertas do mercado por meio de sensações, como: ouvir, ver, provar, cheirar e tocar, não foi identificado nenhum elemento na análise, apesar dos questionamentos realizados nesse sentido. Tal resultado pode ter decorrido em função das características dos aplicativos que de uma maneira geral poderiam despertar sensações apenas relacionadas ao sentido da visão, ou seja, considerando a disposição das informações dos aplicativos, uso de figuras, mapa de localização, configuração, etc., tendo em vista que os aplicativos analisados não emitem sinais sonoros e os demais sentidos não se aplicam. Diferente do estudo de Madzharov, Block e Morrin (2015) que demonstraram em seus estudos que o estímulo sensorial olfativo, o uso de perfume, influencia o comportamento de compra.

Já com relação aos "Processos cognitivos", buscamos identificar a percepção dos entrevistados sobre os atributos, benefícios, prejuízos e associações no uso do aplicativo. Sobre esse ponto fizemos o questionamento aos entrevistados: "Você acha fácil ou difícil utilizar esse aplicativo?" Todos os entrevistados responderam que tinham facilidade ao mexer no aplicativo, porém ao seguirmos com a pergunta: "Quais características do aplicativo que levam a essa facilidade?", surgiram os seguintes elementos: prático, simples, dinâmico, autoexplicativo. Estas características indicam que o aplicativo avaliado não demanda muito esforço cognitivo para a sua utilização. Tal fato pode decorrer da familiaridade do público entrevistado, composto por universitários, que utiliza cada vez mais esse tipo de tecnologia para realizar diversos tipos de atividades. Neste sentido, a semelhança na formatação e apresentação dos aplicativos considerados nesta pesquisa, Uber e 99, tornam a utilização desses quase intuitiva.

Em seguida, nós perguntamos: “Já passou por algum problema ao usar o aplicativo?" Foram identificados os seguintes problemas: demora no atendimento, cancelamento da viagem, identificação de 
localização pelo GPS. Alguns relatos semelhantes como de E2 e E9 envolvem os problemas apontados. O E2, por exemplo, fala: "Já aconteceu de solicitar o Uber ou 99 e demorar tanto pra chegar o carro que acabei cancelando a corrida... Principalmente o 99 que não tem uma grande frota de carros e acaba demorando um pouco mais". E o E9: "Já aconteceu às vezes cancelamento por parte dos motoristas, demora no atendimento e às vezes eles não vêm propositalmente e você acaba pagando uma taxa" (E9). Já o Eıo comenta que "acontece problema de localização do GPS, porque ele não te dá exatamente a distância real", o que termina por gerar informação errada para o consumidor quanto ao tempo de chegada do motorista.

Ainda considerando os "Processos cognitivos", identificamos alguns elementos relacionados aos benefícios proporcionados pelo aplicativo. As respostas obtidas foram: praticidade, agilidade, credibilidade de funcionamento do serviço, facilidade ligada ao deslocamento e ao uso, flexibilidade de pagamento, preço, rapidez no deslocamento. Tais benefícios salientam aspectos funcionais que podem ser compreendidos de uma perspectiva racional. Benefícios emocionais poderão ser observados na categoria "Respostas afetivas", o que reforça a ideia de um consumidor que é conduzido tanto por emoções quanto por ações racionais.

Observamos que os respondentes extrapolaram a questão que era sobre o aplicativo para o serviço como um todo, mostrando dificuldade em separar a experiência do uso do aplicativo da prestação do serviço de transporte. O entrevistado $\mathrm{E}_{5}$, ao perguntarmos quais benefícios o aplicativo trouxe para ele, diz: "Eu acho que agilidade, e o valor é cabível no bolso". Já o respondente E2: "É prático, você apenas digita o endereço ali e já chamou e tem opções de pagamento que qualquer pessoa pode usar, tanto no dinheiro como no cartão de crédito ou débito, então traz uma flexibilidade bem grande nesse aspecto".

Além das percepções apresentadas acima, outro processo cognitivo relacionado ao uso desses aplicativos e é a tomada de decisão referente às escolhas sobre a rota, o carro, a forma de pagamento, etc. Além desse, outro processo ocorre ainda quando o usuário se depara com problemas como o cancelamento de uma viagem pelo motorista ou uma falha na localização. Nesses casos, o usuário precisa encontrar meios de solucionar o problema, seja solicitando uma nova viagem ou buscando comunicar-se com o motorista, o que demanda uma reflexão quanto às alternativas possíveis de solução, o que pode levar até a não utilização do serviço naquele momento.

Considerando o elemento "Respostas afetivas", utilizamos em nosso roteiro as perguntas: Você gosta de utilizar o aplicativo de transporte particular? E o que você sente quando está usando o aplicativo durante a viagem? A partir desses questionamentos, algumas pessoas tiveram dificuldade em responder o que sentiam, ainda assim foram identificados alguns elementos que extrapolam a experiência do uso do aplicativo, de forma estrita, e envolvem a experiência com o serviço 
de uma forma geral. Alguns disseram ter um sentimento de necessidade atendida: "Eu me sinto atendido, né?! Atende muito bem minhas necessidades de ir e vir" (E2), e outros que sentiam sensação de tranquilidade e de alívio: "tenho a sensação de alívio, né?! porque a gente não está no ônibus lotado, no trânsito caótico... pelo menos está ali mais tranquilo" (E6). Após ser perguntado o que sentia e porque utilizava o aplicativo o E9 responde: "Pelo conforto, pela praticidade, e é uma opção muito melhor que o transporte público que é bastante sucateado". Além desses elementos surgiram dois sentimentos relacionados à segurança: $\mathrm{O}$ E3 que é do sexo masculino fala: “Ter várias informações ali online, ao mesmo tempo, sobre o carro, sobre a pessoa, sobre o contato... traz segurança". Já E8 do sexo feminino, disse que sente uma certa insegurança durante a viagem em um determinado caso: “(...) Se eu tô sozinha é um pouco mais complicado, eu não gosto de andar de Uber sozinha porque não me sinto 100\% segura não, mas se eu tô com alguém é tranquilo e principalmente assim, se o motorista conversa, se eu vejo que é uma pessoa simpática, uma pessoa boa." Observamos aqui que o uso do aplicativo desperta sentimentos opostos quanto à segurança, influenciando a experiência do consumidor.

Em seguida, com relação ao elemento "Atividades", foi perguntado quais as atividades desempenhadas no aplicativo desde a solicitação até o fim do trajeto. As respostas que surgiram foram: escolha do trajeto, da forma de pagamento, do carro, solicitação da viagem, observação das informações do motorista e do carro, acompanhamento do tempo da viagem, todos esses processos são feitos até a solicitação do serviço. Ao perguntarmos sobre a utilização do aplicativo durante a viagem, alguns respondentes disseram que utilizavam para visualizar a rota. O E2, por exemplo, disse: "Sim, eu sempre gosto de verificar se o motorista tá indo pela rota certa", assim como o E5: "Sim, quando às vezes eu tenho meio que receio do motorista, aí eu vejo se realmente tá acompanhando a trajetória e tal".

No que se refere ao elemento "Avaliação", a partir da pergunta “como você avalia o(s) aplicativo(s) de transporte particular?", obtivemos respostas relativas a uma avaliação geral do aplicativo: "Acessível e excelente" (E2), facilita a vida cotidiana: “É eu gosto muito, eu acho que facilitou muito minha vida" (E4). Ou ainda, em relação ao serviço como um todo, dois respondentes falaram dos elementos que os levam a dar uma avaliação positiva: "Eu avalio em relação ao motorista, se ele puxou assunto comigo, se foi agradável, se ele se preocupou em relação a sinalização e a velocidade. Só isso. Geralmente é uma avaliação positiva" (E5). Já a entrevistada Eıo:

Eu avalio tipo... normalmente os que eu tenho pego têm sido pessoas bem agradáveis [relação aos motoristas] assim, eu não tive muito problema. (...) carros limpos, organizados, eu avalio tudo. A precisão. Têm vezes que você fica, já fiquei embaixo do meu prédio esperando, sei lá, vinte minutos e você mandar mensagem pro motorista e 
Revista de Gestão Pública

PRÁTICAS E DESAFIOS

ISSN: 2177-124

ele não responder. Então isso, que têm muitos motoristas que já falam: olha, estou em trânsito, estou a caminho, vou demorar tanto, mesmo que o aplicativo diga que ele vai chegar em 5 minutos, aí ele diz que vai demorar um pouco mais. Então, essa questão toda da pessoa dizer: eu tô aqui, estou chegando, eu avalio toda essa questão. A simpatia. Não se é simpático de ficar conversando, mas se é educado. É isso.

A seguir, no Quadro 2, apresentamos uma síntese dos elementos apontados pelos entrevistados na experiência de consumo dos aplicativos.

Quadro 2. Elementos da experiência de consumo de aplicativos de transporte particular

\begin{tabular}{|c|c|c|c|c|c|}
\hline Contexto & Estímulos & Processos cognitivos & Respostas & Atividades & Avaliação \\
\hline $\begin{array}{l}\text { Conexão à } \\
\text { internet } \\
\text { Localização } \\
\text { e horário } \\
\text { do uso do } \\
\text { aplicativo } \\
\text { Segurança } \\
\text { urbana }\end{array}$ & $\begin{array}{l}\text { Não foram } \\
\text { identificados } \\
\text { elementos } \\
\text { nessa } \\
\text { categoria }\end{array}$ & $\begin{array}{l}\text { Percepção dos } \\
\text { atributos, problemas e } \\
\text { benefícios } \\
\text { Tomada de decisão na } \\
\text { solicitação do serviço, } \\
\text { no pagamento. } \\
\text { Reflexão sobre } \\
\text { como solucionar os } \\
\text { problemas quando } \\
\text { estes ocorrem }\end{array}$ & $\begin{array}{l}\text { Ser atendido } \\
\text { Ficar } \\
\text { Tranquilo } \\
\text { Ficar aliviado } \\
\text { Sentir } \\
\text { Segurança } \\
\text { Sentir } \\
\text { Insegurança } \\
\text { Sentir } \\
\text { conforto }\end{array}$ & \begin{tabular}{|l|}
$\begin{array}{l}\text { Escolha do trajeto, } \\
\text { da forma de } \\
\text { pagamento, do } \\
\text { carro. } \\
\text { Solicitação da } \\
\text { viagem } \\
\text { Observação das } \\
\text { informações do } \\
\text { motorista e do carro } \\
\text { Acompanhamento } \\
\text { do tempo da viagem } \\
\text { e da rota } \\
\text { Visualizar a rota } \\
\text { durante a viagem }\end{array}$ \\
\end{tabular} & $\begin{array}{l}\text { Acessível } \\
\text { Satisfeito } \\
\text { Excelente } \\
\text { Facilitador da } \\
\text { vida cotidiana }\end{array}$ \\
\hline
\end{tabular}

Fonte: Elaborado pelas autoras (2018). 
A fim de identificar os significados da experiência de consumo (SCHMITT, 1999) questionamos os entrevistados das seguintes formas: "Como você descreve a experiência de utilização desse(s) aplicativo(s)?" e "o que significa a experiência do uso do aplicativo para você?". Os respondentes sentiram certa dificuldade em falar sobre os significados, e então perguntamos a que eles associavam essa experiência. Surgiram os seguintes significados: praticidade, conforto, economia, segurança (com relação às informações dos motoristas), algo útil, rapidez, facilidade de deslocamento, comodidade, inclusão neste tipo de transporte de pessoas com menor renda. Para a entrevistada E9 significa segurança:

Eu me sinto mais segura desde que o app foi lançado pelo fato de os motoristas serem cadastrados, não que isso signifique segurança total, mas você ter informações sobre quem está te transportando e está registrado para o aplicativo todo esse trajeto é importante e é algo que não acontecia antes com os táxis.

Complementando, o entrevistado E2 traz também a questão da segurança e outros elementos: “Bom, basicamente é segurança, conforto, agilidade, é rápido, você não precisa ficar tempos e tempos esperando um ônibus na parada... tem segurança ao pegar pois todos os motoristas têm sua documentação confirmada pelo sistema, né?!". A seguir apresentamos as considerações finais deste estudo.

\section{CONSIDERAÇÕES FINAIS}

A visão experiencial amplia a ideia do consumo como um fenômeno apenas racional ao reconhecer que aspectos emocionais também afetam o comportamento do consumidor em suas decisões de compra. Alguns estudos buscaram identificar os elementos presentes em uma experiência de consumo trazendo subsídios para a gestão da experiência do cliente, bem como para compreender o papel da experiência no comportamento do consumidor. Nesse sentido, este trabalho buscou analisar a experiência de consumo de usuários de aplicativos voltados à mobilidade urbana, especificamente os de transporte particular.

Esta pesquisa buscou preencher uma lacuna desses estudos no que se refere a sua aplicação a produtos tecnológicos. De maneira geral, os resultados encontrados ratificam os elementos indicados por Lofman (1991), com exceção do elemento "Estímulos sensoriais" que não foi identificado nesta pesquisa. Ainda, conforme Giesler e Venkatesh (2005), concluímos que o uso do aplicativo envolve elementos que extrapolam a perspectiva racional do consumo, incorporando também os aspectos de natureza sociocultural do consumo, significados e sentimentos.

Os diferentes significados informados pelos entrevistados reforçam a questão da individualidade da experiência citada por Schmitt (1999). Os significados e elementos da experiência encontrados sinalizam que o uso desses aplicativos vem preencher mais do que uma ne- 
cessidade funcional de transporte em cidades com o trânsito cada vez mais complicado. Eles atendem outras necessidades, afetivas, relacionadas ao bem estar do consumidor que envolvem conforto, tranquilidade, segurança, comodidade, e ainda inclusão social, considerando-se que o preço possibilita que pessoas com menor renda tenham acesso a esse tipo de serviço que antes só era disponibilizado pelos táxis.

Do ponto de vista prático, observamos que a avaliação do aplicativo pelos consumidores extrapola o uso do aplicativo em si, se estendendo a outras características do serviço, que passam pelo motorista e o veículo utilizado para o transporte. Apesar, dos resultados indicarem que os aplicativos possibilitam uma mobilidade de modo eficiente, de forma acessível e que ainda proporcionam uma experiência, de um modo geral, satisfatória, fatores como precisão no horário de chegada do motorista, localização da chamada, correção de problemas com cancelamento, possibilitariam uma experiência de uso ainda melhor, sendo aspectos a serem observados pelas empresas para que possam melhorar a prestação do serviço de forma a criar mais valor para os consumidores e obter uma vantagem competitiva perante os concorrentes.

Assim, esse estudo contribui para diminuir a lacuna de conhecimento que envolve a compreensão dos elementos que compõem a experiência de consumo de produtos tecnológicos, ao identificar a presença de aspectos emocionais no consumo desses produtos. Salientamos também a necessidade da compreensão dos elementos pelas empresas de forma que possam analisar o comportamento do consumidor com base na experiência e fazer a gestão da experiência a ser oferecida aos clientes.

É necessário, no entanto, lembrar que os resultados encontrados nesta pesquisa não podem ser generalizados, haja vista que a seleção dos entrevistados foi realizada de forma não probabilística. Além disso, o perfil dos entrevistados é muito semelhante, todos são estudantes e praticamente da mesma faixa etária. Desta forma, sugerimos a realização de estudos semelhantes que incluam entrevistados com outros perfis, ou ainda outros tipos de aplicativos. 


\section{REFERÊNCIAS}

ADDIS, M.; HOLBROOK, M. B. On the conceptual link between mass customization and experiential consumption: an explosion of subjectivity. Journal of Consumer Behaviour, v. 1 (1), Jun.. 2001. Disponível em: https://onlinelibrary. wiley.com/doi/pdf/10.1002/cb.53. Acesso em: 22 out. 2017.

\section{ALVARES, L. F. H. Quando risco e sensações encontram-se} na teia: uma investigação empírica da relação entre a busca de sensações e o risco percebido em compras pela web. 2004. 250 f. Tese (Doutorado em Administração)-Instituto COPPEAD de Administração, Universidade Federal do Rio de Janeiro, Rio de Janeiro, 2004. Disponível em: http://www.coppead.ufrj.br/upload/ publicacoes/Tese_Luis_Alvares.pdf. Acesso em: 15 set. 2017.

BARBOSA, L. Cultura, consumo e identidade: limpeza e poluição na sociedade brasileira contemporânea. In: BARBOSA, L.; CAMPBELL, C. (Org.). Cultura, consumo e identidade. Rio de Janeiro: FGV, 2006.

BITNER, M. J. Servicescapes: the input of physical surroundings on customers and employees. In: BATESON, John. Managing services marketing: text and readings. 3 a Ed. Orlando: The Dryden Press, 1992. Disponível em: https://pdfs.semanticscholar. org/2acb/77daf7ba6oeb523c276a8c626of6edo76a12. pdf. Acesso: 12. jan. 2018.

CAPELAS, B. Uber tem 13 milhões de usuários no Brasil. O Estado de São Paulo. Abril, 2017. Disponível em: https:// link.estadao.com.br/noticias/geral,uber-tem-13-milhoes-deusuarios-no-brasil,70001726602. Acesso em: 7 mar. 2018.

CORREA, R. S.; PINTO, M. R.; BATINGA, G. L. A Beleza na escuridão: um "olhar" sobre a experiência de consumo por mulheres deficientes visuais em serviços de beleza e estética. Revista Ciências Administrativas, v. 22, n. 2, p. 371-395, 2016. Disponível em: http://www.spell.org.br/documentos/ ver/44408/a-beleza-na-escuridao--um----olhar----sobre-aexperiencia-de-consumo-por-mulheres-deficientes-visuais-emservicos-de-beleza-e-estetica/i/pt-br. Acesso em: 02. out. 2017.

DAMIAN, I. P. M.; MERLO, E. M. O papel da qualidade do serviço e da imagem da loja na experiência de consumo de serviços automotivos. REGE: Revista de Gestão, São Paulo, v. 21, n. 2, p. 269-282, 2014. Disponível em: < http://www. regeusp.com.br/arquivos/2014.2.7.pdf $>$. Acesso em: 6 set. 2017.

FGV. 29a Pesquisa anual do uso de TI. 2018. Disponível em: https://eaesp.fgv.br/sites/eaesp.fgv.br/files/ 
pesti2018gvciappt.pdf. Acesso em: 10 jul. 2018.

GENTILE, C.; SPILLER, N.; NOCI, G. How to sustain the customer experience: an overview of experience components that co-create value with the customer.

European Management Journal. v. 25, n. 5, p. 395-410, 2007. Disponível em: https://ac.els-cdn.com/S0263237307000886/1s2.0-S0263237307000886-main.pdf? tid=spdf-713f9714c121-4418-9094-f415791ffbog\&acdnat $=1519755261$ e024c8193b642fooa4ed2b1f267boogd. Acesso em: 23 fev. 2018.

GIESLER, M.; VENKATESH, A. Reframing the embodied consumer as cyborg: a posthumanist epistemology of consumption. Advances in Consumer Research, v. 32, p. 1-9, 2005. Disponível em: file:///C:/Users/Acsouza/ Downloads/Reframing the_Embodied_Consumer_ as_Cyborg_A_Posthu.pdf. Acesso em 11 out. 2017.

GUIMARÃES, P. R. B. Métodos quantitativos estatísticos. Curitiba: IESDE Brasil S.A., 2008. Disponível em: http://people.ufpr.br/ prbg/public html/ ceoo3/LIVRO1.pdf. Acesso em: 17 abr. 2018.

HOLBROOK, M. B. The millennial consumer in the texts of our times: experience and entertainment. Journal of Macromarketing. v. 20, n. 2, p. 178-192, Dec. 2000. Disponível em: https://db.tt/g2ds]Mrp28. Acesso: 22. nov. 2017.

$\therefore$ HIRSCHMAN, E. The experiential aspects of consumption: consumer fantasies, feeling and fun. Journal of Consumer Research, v. 9, n. 2, p. 132-141, Sept. 1982. Disponível em: http://www.mastermarketing. dauphine.fr/fileadmin/mediatheque/masters/master204/ documents/Holbrook - 10.pdf. Acesso em 20 set. 2017.

KANTAR TNS. E-hailing puts the brakes on traditional mobility. Disponivel em: http://www. tnsglobal.com/press-release/e-hailing-puts-brakestraditional-mobility. Acesso em: 19 set. 2017.

KRANZBÜHLER, A-M.; KLIJNEN, M. H. P..; MORGAN, R. E.; TEERLING, M. The multilevel nature of customer experience research: an integrative review and research agenda. International Journal of Management Reviews, v. 20, p. 433-456, 2018. Disponível em: https://onlinelibrary.wiley. com/doi/epdf/10.1111/ijmr.12140. Acesso em: 1o set. 2019.

LI, M.; DONG, Z. Y.; CHEN, X. Factors influencing consumption experience of mobile commerce. Internet Research, v. 22, n. 2, p. 120-141, 2012. Disponível 
em: https://www.emerald.com/insight/content/

doi/10.1108/10662241211214539/full/html. Acesso em 12 set. 2019.

LOFMAN, B. Elements of experiential consumption: an exploratory study. Advances in Consumer Research, v. 18. 1991. Disponível em: http://acrwebsite.org/volumes/7243/ volumes/v18/NA-18. Acesso em: og nov. 2017.

MADZHAROV, A.; BLOCK, L.; MORRIN, M. The cool scent of power: effects of ambient scent on consumer preferences and choice behavior. Advances in Consumer Research, v. 42, p. 593-595, 2015. Disponível em: https://journals.sagepub. com/doi/10.1509/jm.13.0263. Acesso em: 13 set. 2019.

MCCARTHY, J.; WRIGHT, P. Technology as experience. Cambridge: The MIT Press, 2004. Disponível em: https://www.researchgate.net/publication/224927635 Technology as Experience. Acesso em: 14 fev. 2018.

PALMER, A. Customer experience management: a critical review. Journal of Services Marketing. v. 24, n. 3, p. 196-208, 2010. Disponível em: http://wwwemeraldinsight-com.ezig.periodicos.capes.gov.br/doi/ pdfplus/10.1108/08876041011040604. Acesso em: 14 fev. 2018.

SCHMITT, B. H. Experiential Marketing. In: Journal of Marketing Management. n. 15. [S.1]: Westburn Publishers Ltd, 1999. Disponível em: https://www.tandfonline.com/doi/ pdf/10.1362/026725799784870496. Acesso em: 22 out. 2018.

. Marketing experimental. São Paulo: Nobel, 2000.

Disponível em: https://books.google.com.br/books?hl=pt$\underline{\mathrm{PT} \& l \mathrm{r}=\& \mathrm{id}={ }_{5 j} \mathrm{X} \quad \mathrm{uz}-\mathrm{dzP}{ }_{4} \mathrm{C} \& \mathrm{oi}=\mathrm{fnd} \& \mathrm{pg}=\mathrm{PT} 12 \& \mathrm{dq}=\mathrm{Schmitt}+20}$ oo + marketing + experimental\&ots $=\mathrm{a} \quad 37 \mathrm{ruwD} 8$ [\&sig $=5 \mathrm{lvvWSF}$ Bjwlul51DscYbYSrhzNk\#v=onepage\&q=Schmitt $\% 202000 \% 20$ marketing\%20experimental\&f=false. Acesso em: 23. set. 2017.

Gestão da experiência do cliente:

uma revolução no relacionamento com os Consumidores. Porto Alegre: Bookman, 2004.

SOUZA, R. V. Comportamento do consumidor e consumo de tecnologia: perspectivas de investigação na sociedade contemporânea. In: Encontro de Marketing da ANPAD, IV, 2010, Florianópolis. Anais... Florianópolis, 2010. Disponível em: http://www.anpad.org.br/admin/ pdf/ema338.pdf. Acesso em: 12 dez. de 2017.

TOMTOM. TomTom Traffic Index. Full ranking 2017. Disponível em: https://www.tomtom.com/en gb/traffic- 
index/ranking/?country=BR. Acesso em: 29 jul. 2019.

ZILLES, F. "Se meu jipe falasse: a experiência de consumo dos usuários off-road." 2006. 172 f. Dissertação (Mestrado em Administração)-Escola de Administração, Programa de Pósgraduação em Administração, Universidade Federal do Rio Grande do Sul, Porto Alegre, 2006. Disponível em: http:// www.lume.ufrgs.br/bitstream/handle/10183/6197/000526782. pdf?sequence $=1$. Acesso em: 7. set. 2017.

PINE, J; GILMORE II, J. H. Welcome to the experience economy. Harvard Business Review. v. 76, July-August, 1998. As autoras agradecem ao Conselho Nacional de Desenvolvimento Científico e Tecnológico (CNPQ) pelo apoio durante a pesquisa. 